\title{
Results from the Danish monitoring programme for pesticide residues from the period
} 2004-2011

Poulsen, Mette Erecius; Andersen, Jens Hinge; Petersen, Annette; Jensen, Bodil Hamborg

Published in:

Food Control

Link to article, DOI:

10.1016/j.foodcont.2016.11.022

Publication date:

2017

Document Version

Peer reviewed version

Link back to DTU Orbit

Citation (APA):

Poulsen, M. E., Andersen, J. H., Petersen, A., \& Jensen, B. H. (2017). Results from the Danish monitoring programme for pesticide residues from the period 2004-2011. Food Control, 74, 25-33.

https://doi.org/10.1016/j.foodcont.2016.11.022

\section{General rights}

Copyright and moral rights for the publications made accessible in the public portal are retained by the authors and/or other copyright owners and it is a condition of accessing publications that users recognise and abide by the legal requirements associated with these rights.

- Users may download and print one copy of any publication from the public portal for the purpose of private study or research.

- You may not further distribute the material or use it for any profit-making activity or commercial gain

- You may freely distribute the URL identifying the publication in the public portal 


\section{Accepted Manuscript}

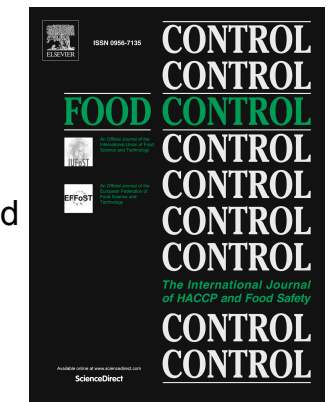

Results from the Danish monitoring programme for pesticide residues from the period 2004-2011

Mette Erecius Poulsen, Jens H. Andersen, Annette Petersen, Bodil H. Jensen CONTROL

PII: S0956-7135(16)30636-3

DOI: 10.1016/j.foodcont.2016.11.022

Reference: JFCO 5352

To appear in: Food Control

Received Date: 1 September 2016

Revised Date: 14 November 2016

Accepted Date: 15 November 2016

Please cite this article as: Poulsen M.E., Andersen J.H., Petersen A. \& Jensen B.H., Results from the Danish monitoring programme for pesticide residues from the period 2004-2011, Food Control (2016), doi: 10.1016/j.foodcont.2016.11.022.

This is a PDF file of an unedited manuscript that has been accepted for publication. As a service to our customers we are providing this early version of the manuscript. The manuscript will undergo copyediting, typesetting, and review of the resulting proof before it is published in its final form. Please note that during the production process errors may be discovered which could affect the content, and all legal disclaimers that apply to the journal pertain. 


\title{
1 Results from the Danish monitoring programme for pesticide residues from the period $2004-2011$
}

\begin{abstract}
The Danish pesticide residue monitoring programme evaluates compliance with the maximum residue levels established by the EU and monitors the residue levels in foods to enable an evaluation of the exposure of the Danish population to pesticides. The latter part of the programme included 25 different fruits, vegetables and cereals and processed foods. The commodities were chosen based on their contribution to the intake of pesticides in the Danish population. A total of 17,309 samples were collected during 2004-2011.. The monitoring showed that the frequencies of pesticides were higher in samples of foreign origin than in samples of Danish origin both for samples with residues above or below the MRLs. Overall, pesticide residues were more frequently found in fruits and vegetables than the other groups of commodities; fruits had higher frequencies than vegetables. Residues above the MRLs were found in $2.6 \%$ of the samples. In plant commodities, 163 different substances were found in measurable concentrations. Residues of more than one pesticide (multiple residues) were found in $27 \%$ of all samples. A comparison of the frequencies of pesticide residues in commodities from different countries showed that Danish commodities with a lower frequency of pesticides.
\end{abstract}

\section{Keywords}

Pesticide residues

Monitoring programme

Sampling plan

Pesticide residue analysis

Maximum Residues Levels

\section{Introduction}

Although food and health authorities worldwide ensure that the risk of exposure to pesticide residues in food is very limited for residues below the maximum residue limits, MRL (EU - Pesticides database, 2016), Danish consumers are in general very concerned about pesticide residues in foods. The focus of the Danish consumers is not explicitly on residues above the MRLs but on how often pesticides are found and how to avoid foods with pesticide residues.

Since the beginning of the 1960s, Denmark has monitored fruit and vegetables for pesticide residues. The Danish monitoring programme for foods was established in 1983. The results are reported for periods of 5-8 years. This paper covers the fifth period, 2004-2011. The programme included commodities of fruit, vegetable, cereal and animal origin.

The aim of the Danish monitoring programme is to evaluate compliance with the maximum residue levels established by the EU (The European Parliament, 2005) and to monitor the residue levels in foods to enable an evaluation of the dietary exposure of the Danish population to pesticides (Poulsen, Andersen, Petersen, \& Hartkopp, 2005).

This paper describes and compares in detail the 2004-2011 monitoring results to show the different factors that influence the exposure of the Danish population to pesticides. After describing the design of the monitoring programme, the sampling and analytical methods used are described, and a comparison of the frequency of samples with residues below and above MRLs between Danish, EU- and non-EU-produced commodities is shown, as well as the frequency of samples and commodity types with multiple residues. Additionally, the types of pesticides found in fruit, vegetables and cereals are listed. Finally, a detailed comparison of the frequencies of pesticide residues in commodities produced in different countries is presented. All residue data can be found in the Appendix.

Although pesticide control programmes is implemented in many countries for many years, the amount of peer reviewed literature on results from pesticide residue monitoring in general is limited, since this type of data is usually published in reports and are often not in English language. Peer reviewed articles on food control results of pesticide 
residues covers typically only one commodity like honey, tomatoes, wine, citrus fruits (Arias, Bojacá, Ahumada, \& Schrevens, 2014; Bargańska, Ślebioda, \& NamieŚnik, 2013; Čuš, Česnik, Bolta, \& Gregorčič, 2010; Juan-Borrás, Domenech, \& Escriche, 2016; Ortelli, Edder, \& Corvi, 2005; Rodríguez López, Ahumada, Díaz, \& Guerrero, 2014; Uygun, Koksel, \& Atli, 2005), limited number of commodities e.g. fruits (Oliva, Gemal, Nóbrega, \& Araújo, 2003), limited number of samples (Knežević \& Serdar, 2009), or limited number of pesticides (Chen et al., 2011). Thus comparison of the overall results to other published data is primarily done against results from EU (EFSA, 2013, 2014) and USD (U.S. FDA, 2010; U.S. Food and Drug Administration, 2011).

The residue data presented here have been combined with Danish consumption data for different consumer groups, and dietary exposure calculations have been estimated and published in another paper by Jensen et al., 2015.

\section{Materials and methods}

\subsection{Design of sampling plan}

The sampling plan for the period 2004 to 2006 was structured in the same manner as for the period 1998-2003. A detailed description can be seen in Poulsen et al. (2005). In 2006, the design of the sampling plan was changed, and it has remained the same since then. The sampling plan for fruit and vegetables was drafted in two parts. The first part was designed to enable estimation of the exposure to pesticides and included 25 different fruits, vegetables and cereal commodities as well as processed foods such as wine. The commodities were chosen based on their contribution to the intake of pesticides in the Danish population calculated using the monitoring results from the period 1998-2003 (Poulsen et al., 2005). For these commodities, a fixed number of 50 samples per year were collected. Additionally, 15 samples of commodities referenced in the EU Multiannual Pesticide Control Programme (EU Commission, 2008) were included. Part two included samples that contributed less to the intake of pesticides but was focussed specifically on the compliance with MRLs or labelling of the production method, e.g., organically grown, produced without growth regulators or surface treatment. Part one comprised $70 \%$ fruit and vegetable samples and $15 \%$ cereal samples. The remaining $15 \%$ of the samples were of animal origin, including milk, honey, baby food and organic commodities. The results from these samples are not included in the comparisons, but all results are listed in the Appendix.

\subsection{Samples}

Authorised personnel from the regional food control units under the Danish Veterinary and Food Administration performed the sampling and collected the samples randomly within each commodity. The sampling procedure conformed to the EU directive on sampling for the official control of pesticide residues (EU Commission, 2002). The samples were mainly taken at wholesalers, importers, slaughterhouses and at food processing companies.

The sampling of meat and other products of animal origin is regulated by Council Directive 96/23/EC (EU Commission, 1996). The aim of this directive is to ensure that the Member States monitor primarily their own production of commodities of animal origin for different substances, e.g., pesticides. However, imported samples from non-EU countries shall also be monitored. Depending on the animal species, the number of samples was between $0.03-0.15 \%$ of the production or import.

The aim has been to monitor the commodities representative of the Danish market, and for this reason more samples produced in EU Member States and non-EU countries were collected than samples of Danish origin. Thus, one-third of the plant origin samples were of Danish origin. For animal origin samples, more than $90 \%$ of the samples were of Danish origin as described by EU regulation 96/23 (EU Commission, 1996).

A total of 17,309 samples were collected over eight years. The number of fruit, vegetable and cereal samples increased, whereas the number of samples of animal origin decreased slightly during the period (see Figure 1). Most of the samples were conventionally grown fresh fruits and vegetables (70\%), but conventionally grown cereals (10\%) and samples of animal origin (11\%) were also collected. In addition, $6 \%$ samples of organically grown crops (fresh, 
frozen, processed) were collected, as well as processed foods (e.g., wine) and samples of baby food (see Table 1). Approximately $30 \%$ of the fruits, vegetables and cereals; $80 \%$ of the meat; and $100 \%$ of the milk were of Danish origin, whereas $99 \%$ of the wine was produced outside Denmark. Almost 175 different fruit, vegetable and cereal commodities were sampled; of these, 73 were also organically produced. Detailed results have been published each year in the period 2004-2011 (Christensen et al., 2007, 2008; Christensen, Petersen, Poulsen, Grossmann, \& Holm, 2006; Danish Veterinary and Food Administration, 2005; Jensen et al., 2010, 2011, 2012; Petersen et al., 2009).

[Insert Table 1 around her]

The number of samples was low compared directly with other EU countries. However, despite the low number of samples, Denmark was among the top four European Union (EU) Member States when comparing the number of samples taken related to the population size (EFSA, 2013). In 2010, Denmark collected 40 samples per 100,000 inhabitants. Only Iceland (86), Cyprus (84) and Slovenia (60) collected more samples than Denmark (EFSA, 2013). In 2010 , the average number of monitoring samples per inhabitant in the EU was 14 , and, for comparison, the number was 2.6 in the USA (U.S. FDA, 2010).

[Insert Figure 1 around here]

\subsection{Analysis}

The samples were mainly analysed at the Regional Food Laboratories. However, a few of the samples were analysed at the National Food Institute of the Technical University of Denmark. All laboratories involved in the monitoring were accredited to perform pesticide analysis in accordance to (International Standard Organization, 2005)by the Danish body of accreditation, DANAK.

Analytical methods were developed and documented at the National Food Institute of the Technical University of Denmark. Fruits and vegetables were analysed by up to five different analytical methods covering an increasing number of pesticides over the years, from 149 to 238 pesticides. Cereals were analysed by three different methods covering 105-166 pesticides, and meat was analysed by one method covering 30-44 pesticides. The multi-methods have changed over the period, but all methods were accredited. The GC-amendable pesticides for fruit and vegetables were based on an acetone/ethylacetate/cyclohexan extraction which in 2010 was changed to acetonitril extraction (QUEChERS). The LC-amendable pesticides for fruit and vegetables were based on a methanol extraction. In addition to the multi methods, three single-residue methods were used. One included carbendazim/thiabendazole until these pesticides were included in the LC-multimethod. Furthermore, two methods for dithiocarbamate and chlormequate/mepiquate were used. Cereals were analysed with a GC multi-method based on ethylacetate extraction and two single-residue methods covering chlormequate/mepiquate and glyphosate. Samples of animal origin were analysed by a GC multimethod based on acetone/ethylacetate/cyclohexan extraction.

\section{Results and discussion}

\subsection{Pesticide residues}

The results for the eight years of monitoring show that more residues were found in samples of foreign origin than in samples of Danish origin (see Figure 2) for both samples with residues above and below the MRLs. Overall, fruits and vegetables had higher frequencies of residues than the other groups of commodities; fruits had higher frequencies than vegetables. Overall, residues above the MRLs were found in $2.6 \%$ of the samples, most frequently in fruits.

The Danish results are in accordance with the results reported by the EU for 2010 and 2011, in which the exceedance rate for samples from the EU and EFTA was at 1.5\%. For samples that originated from non-EU countries, the exceedance rates were $6.0 \%$ and $4.7 \%$ for 2010 and 2011, respectively (EFSA, 2013, 2014). The results were also in accordance with findings in the USA, where the exceedance rates for import samples were 4.9 and 7.1 (U.S. FDA, 2010; U.S. Food and Drug Administration, 2011). 
In plant commodities, 163 different substances were found in measurable concentrations. The residues exceeding the legal limits included 33 different pesticides. The pesticides which were detected in at least $1 \%$ of the samples of plant products are presented in Figure 3. Malathion was the pesticide analysed in the most samples $(16,806)$. Imazalil was the pesticide most frequently found ( $14 \%$ of the samples), while dithiocarbamates and carbendazim were the pesticides that exceeded the MRLs most frequently $-0.54 \%$ and $0.46 \%$ of the samples, respectively.

[Insert Figure 3 around here]

\subsection{Multiple residues}

Residues of more than one pesticide (multiple residues) were found in $27 \%$ of all samples and in 98 different commodities (see Figure 4). Correspondingly, the EU reported $27 \%$ of samples having multiple residues in both 2010 and 2011 (EFSA, 2013, 2014).

In particular, citrus fruits contained multiple residues in more than $75 \%$ of the samples, which was a higher frequency than the 63\% and 60\% found in the EU in 2010 and 2011, respectively (EFSA, 2013, 2014). The samples with the highest number of pesticides were two chili peppers from Thailand, where 10 different pesticides were detected. Another chili sample from Thailand contained nine different pesticides, and this was also the case for two table grape samples from Italy and Chile. Samples with eight detected pesticides included three samples of chili peppers (Spain, Thailand and Vietnam), two samples of lettuce (Belgium and France), and one sample of apple (France), pear (Belgium) and peas with pods (Kenya). It should be emphasised that it is not necessarily an individual fruit or vegetable that contained all the detected pesticides because the analysed samples can comprise more than one fruit or vegetable, e.g., 10 individual fruits. The composite sample can also consist of commodities produced by different growers. Table 2 shows the commodities with multiple residues and for which more than 30 samples were analysed for the period 2004-2011.

[Insert Figure 4 around here] [Insert Table 2 around here].

\subsection{Detailed evaluation of pesticide residues in commodities produced in different countries.}

The commodities consumed in Denmark are produced in many different countries, and the monitoring data were evaluated to determine any differences in the frequencies of samples with residues of Danish and foreign origin or between countries. Here, foreign origin signifies countries outside Denmark. For the commodities that contributed most to the exposure of pesticides for Danish consumers, the frequency of residues in samples has been compared between countries. Only commodities for which more than 10 samples from the same country were analysed are included in this evaluation. The results included in the evaluation below were tested by a chi-square test to if differences seen between countries were statistically significant. For bananas, grapefruit, lemon, mandarins/clementines and oranges no significant differences were seen, due to the low number of samples without pesticide residues. For the rest of the commodities a significant differences were seen with CHITEST values $<0.05$. The highest values were for apple (0.022) and strawberries (0.011).

The frequency of residues found in Denmark is also compared with the frequencies found by the EU monitoring programme. Because the EU monitoring programme is a rolling programme, all commodities are not analysed every year; therefore, a comparison has been performed for the years 2009, 2010 and 2011. 
Bananas were mainly imported from Columbia, Costa Rica and Ecuador, and pesticides were found in $85 \%$ of the 425 samples. The banana samples had residues of 14 different pesticides; the pesticides most frequently found were imazalil and thiabendazole. In 2009 in the EU, an average of 57\% of the banana samples had residues of 35 different pesticides, most frequently imazalil, thiabendazole, chlorpyrifos and azoxystrobin (EFSA, 2011).

The main exporters to the Danish market of grapefruit were South Africa, Turkey, the USA and Israel, and pesticides were found in $99 \%$ of the 388 samples. The grapefruit samples had residues of 46 different pesticides, most frequently imazalil, orthophenylphenol and chlorpyrifos.

Most of the lemon and mandarin/clementine samples originated from Spain. Pesticide residues were found in $97 \%$ of the 388 lemon samples, 39 different pesticides were found and the most frequently found pesticides were imazalil and chlorpyrifos. Pesticide residues were found in $99 \%$ of the 411 mandarin samples, 55 different pesticides were found, and the most frequently found pesticides were imazalil and chlorpyrifos as for lemons. In 2011 in the EU, an average of $85 \%$ of the mandarin samples had residues of 59 different pesticides, most frequently imazalil, chlorpyrifos and thiabendazole (EFSA, 2014).

The samples of orange originated mainly from Spain, Greece, South Africa and Morocco. Pesticide residues were found in $98 \%$ of the orange samples. Forty-nine different pesticides were found, and here the most frequently found were also imazalil and chlorpyrifos. In 2011 in the EU, an average of $80 \%$ of the samples had residues of 73 different pesticides, the most frequently found being imazalil, bromide ion and chlorpyrifos (EFSA, 2014).

Figure 5 shows the frequencies of pesticide residues for 18 different commodities where we found significant differences in the frequencies between different countries. Below is a short summary of the results for each commodity.

[Insert figure 5 around here]

Apples are the commodity that contributes the most to the pesticide intake of the Danish consumer (Jensen et al., 2015). This is due to the high consumption of apples, the high frequency of pesticide residues in apples and main method of eating apples raw with the peel. For most pesticides a major part of the content can be found in the peel. Apples are therefore controlled frequently, and all together 585 samples were collected and analysed. Approximately $35 \%$ of the samples originated from Denmark, and approximately $20 \%$ originated from Italy and France. The remaining $25 \%$ originated from 7 other countries (see Figure 5). The frequencies of pesticide residues ranged from $46 \%$ (Denmark) to $100 \%$ (Chile and Brazil). The apple samples had residues of 54 different pesticides, most frequently chlorpyrifos, diphenylamine and carbendazim. In 2010 in the EU, an average of $68.4 \%$ of the samples had residues of 94 different pesticides, most frequently found dithiocarbamates, captan/folpet (sum) and diphenylamine (EFSA, 2013).

Approximately $30 \%$ of the collected pear samples in the period 2004-2011 were of Danish origin, and another $30 \%$ originated from the Netherlands. In total, 466 pear samples were collected. The frequencies of pesticide residues ranged from 55\% (Denmark) to 100\% (Belgium). The pear samples had residues of 48 different pesticides, most frequently pyraclostrobin, chlormequat and dithiocarbamates. In 2011 in the EU, an average of $70.8 \%$ of the samples had residues of 66 different pesticides, most frequently dithiocarbamates, boscalid and pyraclostrobin (EFSA, 2014).

Half of the peach and nectarine samples originated from Italy and Spain. Peaches and nectarines are not grown commercially in Denmark. In total, 678 samples of peaches and nectarine were collected, and the frequencies of pesticide residues ranged from $62 \%$ (Spain) to $92 \%$ (Chile). The peaches and nectarine samples had residues of 40 different pesticides, most frequently tebuconazole, iprodione, carbendazim and chlorpyrifos. In 2010 in the EU, an average of $73.0 \%$ of the samples had residues of 79 different pesticides, most frequently tebuconazole followed by dithiocarbamates and iprodione (EFSA, 2013). 
Plums are grown in Denmark, and approximately $20 \%$ of the collected samples were of Danish origin. Most of the foreign samples originated from Spain, South Africa and Chile, covering approximately one-third of the samples taken. In total, 391 samples of plums were collected, and the frequencies of pesticide residues ranged from 15\% (Argentina) to $85 \%$ (Chile). The plum samples had residues of 31 different pesticides. The most frequently found pesticides were iprodione, tebuconazole and chlorpyrifos.

Strawberries are grown in Denmark, and approximately $40 \%$ of the samples were of Danish origin in the period 20042011. The main part of the samples (45\%) was produced in Spain, Poland, Germany and Belgium. In total, 429 strawberries samples were collected, and the frequencies of pesticide residues ranged from $50 \%$ (China and Poland) to $85 \%$ (Belgium). The strawberry samples had residues of 45 different pesticides, most frequently cyprodinil, fenhexamid and pyraclostrobin. In 2010 in the EU, an average of $67.9 \%$ of the samples had residues of 82 different pesticides, most frequently cyprodinil followed by fludioxonil and boscalid (EFSA, 2013).

Most of the table grapes samples originated from South Africa, Italy, Chile, India and Spain (77\%). The commodity table grape is not grown commercially in Denmark. In total, 460 samples of grapes were collected, and the frequencies of pesticide residues ranged from $55 \%$ (Brazil) to $91 \%$ (Chile). The grape samples had residues of 54 different pesticides, most frequently fenhexamid, iprodione and cyprodinil. In 2009 in the EU, an average of $73.3 \%$ of the samples had residues of 76 different pesticides, most frequently fenhexamid, followed by cyprodinil and boscalid 258 (EFSA, 2011).

Cucumbers are grown in Denmark, and approximately 50\% of the collected samples were Danish cucumbers. Most of the foreign-produced samples originated from the Netherlands and Spain (50\%). In total, 417 cucumber samples were collected, and the frequencies of pesticide residues ranged from 38\% (Denmark) to $85 \%$ (Spain). The cucumber samples had residues of 36 different pesticides, most frequently azoxystrobin and propamocarb. In 2011 in the EU, an average of $47.0 \%$ of the samples had residues of 67 different pesticides, most frequently bromide ion and propamocarb (EFSA, 2014).

Tomatoes are grown in Denmark, and approximately $45 \%$ of the collected samples were of Danish origin. Most of the foreign-produced samples originated from Spain and the Netherlands (45\%). In total, 462 samples of tomato were collected and analysed. The Danish tomatoes had residues of six different pesticides in only $5 \%$ of the samples, with none above the MRLs. The frequencies of pesticide residues in the samples of foreign origin ranged from $33 \%$ (the Netherlands) to $82 \%$ (Spain). The tomato samples had residues of 48 different pesticides, most frequently procymidone, cyprodinil and iprodione. In 2010 in the EU, an average of $48.9 \%$ of the samples had residues of 84 different pesticides, most frequently bromide ion, followed by dithiocarbamates and cyprodinil (EFSA, 2013)

Sweet peppers are hardly grown commercially in Denmark. Only two samples were analysed, and both contained fenhexamid. Most of the samples originated from the Netherlands and Spain. In total, 387 sweet pepper samples were collected, $72 \%$ of them being Dutch or Spanish in origin. The frequencies of pesticide residues ranged from $11 \%$ (Netherland) to $81 \%$ (Turkey). The sweet pepper samples had residues of 52 different pesticides where the most frequently found were flutriafol, procymidone and azoxystrobin. In 2009 in the EU, an average 34.5\% of the samples had residues of 79 different pesticides, most frequently imidacloprid, flutriafol, and triadimefon (EFSA, 2011)

Lettuce is grown in Denmark, and approximately 50\% of the collected samples in the period 2004-2011 were covered by Danish lettuce. One-third of the samples originated from Spain and Germany. In total, 371 lettuce samples were collected, and the frequencies of pesticide residues ranged from 13\% (Denmark) to $65 \%$ (the Netherlands). The lettuce samples had residues of 36 different pesticides, most frequently dithiocarbamates and cyprodinil. In 2010 in the EU, an average of $57.6 \%$ of the samples had residues of 68 different pesticides, most frequently bromide ion, 
Spinach is grown in Denmark, and approximately 30\% of the collected samples in the period 2004-2011 were covered by Danish spinach. Half of the samples originated from Italy and Germany. In total, 244 spinach samples were collected, and the frequencies of pesticide residues ranged from 17\% (Belgium) to 69\% (Spain). The spinach samples had residues of 28 different pesticides, most frequently bromide ion, lambda-cyhalothrin and deltamethrin. In 2011 in the $\mathrm{EU}$, an average of $46.7 \%$ of the samples had residues of 50 different pesticides, most frequently bromide ion and dithiocarbamates (EFSA, 2014).

Most of the beans with pod samples originated from Kenya, Germany, Egypt, the Netherlands and Morocco. In total, 311 bean samples were collected, and the frequencies of pesticide residues ranged from 29\% (Egypt) to $75 \%$ (Netherland). The bean samples had residues of 43 different pesticides, most frequently cyprodinil and azoxystrobin. In 2011 in the EU, an average of $46.1 \%$ of the samples had residues of 64 different pesticides, most frequently bromide ion, boscalid and iprodione (EFSA, 2014).

Carrots are grown in Denmark, and approximately $70 \%$ of the collected samples were covered by Danish carrots. Most of the foreign samples originated from Italy and Germany, covering $20 \%$ of the samples taken. In total, 499 carrot samples were collected and analysed, and the frequencies of pesticide residues ranged from $0 \%$ (Belgium) to $43 \%$ (Italy). The carrot samples had residues of 19 different pesticides, most frequently linuron. In 2011 in the EU, an average of $42.7 \%$ of the samples had residues of 51 different pesticides, frequently bromide ion, boscalid and linuron (EFSA, 2014).

Potatoes are grown in Denmark, and approximately $85 \%$ of the collected samples were covered by Danish potatoes. Only $9 \%$ originated from the United Kingdom, France and Spain. In total, 669 potato samples were collected, and 424 were from Denmark. In the potato samples of Danish origin four different pesticides were found in only $2 \%$ of the samples, none above the MRLs. One of the pesticides was quintozene, which is a pollutant in the soil from earlier uses. The frequencies of pesticide residues in samples of foreign origin ranged from $14 \%$ (UK) to $54 \%$ (France). The potato samples had residues of 7 different pesticides, most frequently chlorpropham, propamocarb and metalaxyl. In 2011 in the $\mathrm{EU}$, an average of $23.8 \%$ of the samples had residues of 30 different pesticides, most frequently bromide ion, chlorpropham and propamocarb (EFSA, 2014).

The volume of red wine produced in Denmark is very small. Only two samples were analysed, and no pesticide residues were found. Most of the samples originated from Argentina, Chile, France, Italy and Spain. In total, 268 samples of red wine were collected. The frequencies of pesticide residues ranged from $15 \%$ (USA) to $87 \%$ (Argentina). The wine samples had residues of 16 different pesticides, most frequently carbendazim, dimethomorph and fenhexamid. Wine was not included in the EU multi-annual pesticide control programme before 2013. However, in 2013 an average of $45.0 \%$ of the white and red wine samples had residues of 37 different pesticides, most frequently boscalid, followed by dimethomorph and fenhexamid (EFSA, 2015)

Wheat is grown in Denmark, and approximately $40 \%$ of the wheat flour samples were of Danish origin. For approximately $38 \%$ of the analysed samples the origin was unknown. In total, 143 samples of wheat flour were collected, and the frequencies of pesticide residues ranged from 22\% (Denmark) to 84\% (Germany). The wheat flour samples had residues of 7 different pesticides, most frequently chlormequat. In 2011 in the EU, an average of 52.1\% of the samples had residues of 18 different pesticides, most frequently found chlormequat and pirimiphos-methyl (EFSA, 2014).

Samples of wheat kernels were also collected, and approximately $50 \%$ of the wheat kernel samples were of Danish origin. In total, 442 samples were collected, and the frequencies of pesticide residues ranged from $22 \%$ (Denmark) to $41 \%$ (Germany). The wheat kernel samples had residues of 9 different pesticides, most frequently chlormequat and pirimiphos-methyl. In 2009 in the EU, an average of $32.2 \%$ of the samples had residues of 38 different pesticides, most frequently chlormequat and pirimiphos-methyl (EFSA, 2011). 
Oat is grown in Denmark, and approximately $40 \%$ of the samples of rolled oats were of Danish origin. For approximately $30 \%$ of the analysed samples the origin was unknown. Samples from Germany, Sweden, and the United Kingdom were collected and analysed. In total, 184 samples of rolled oats were collected, and the frequencies of pesticide residues ranged from $4 \%$ (Denmark) to $84 \%$ (Germany). The oat samples had residues of 6 different pesticides, most frequently chlormequat. In 2010 in the EU, an average of $54.4 \%$ of the samples had residues of 20 different pesticides, most frequently chlormequat, glyphosate and pirimiphos-methyl (EFSA, 2013).

The differences in the pesticide residue frequencies of samples originating from different countries indicate that if Danish consumers chose commodities of Danish origin, they would have had a lower exposure to pesticides. This is especially the case for apples, pears, cucumbers, tomatoes, lettuce, spinach, potatoes, wheat flour and rolled oats. The reasons for the lower frequencies of pesticide residues in commodities of Danish origin are due to several factors. Denmark has for many years had a stricter regulation on pesticide use, and the pest pressure in Denmark is lesser than in countries with a warmer climate. In addition, the use of biological pest control is common for commodities grown in greenhouses. Dietary exposure calculations have shown that choosing Danish-produced commodities whenever possible could reduce the exposure and the Hazard Index by a factor of approximately 2 (Jensen et al., 2015).

When looking at the frequency profile for the different commodities shown in Figure 5, more or less same profile was found for apple, pear, peaches and nectarines, strawberries, table grapes in the pesticide residue with frequencies between $50-100 \%$. All these commodities are grown in open fields. The rest of the commodities pesticide residues were found 2-7 times more frequently in samples from the country with the highest frequency compared with the country with the lowest frequency. For cucumber, tomatoes, sweet peppers, lettuce, spinach the larger differences could result from that the commodities in some of the countries (with low frequencies) were grown in greenhouses, where pest can be controlled by biological treatment instead of by pesticides. However, plums, beans with pods, carrots, potatoes, the grape used for producing red wine and the cereals are grown in open fields in all countries. The explanation could be different pests, different treatment practices or different approval of pesticides to use in the production.

[Insert Table 3 around here]

\subsection{General remarks on the pesticide residue findings and human health.}

Regulation (EC) 1107/2009 (EU Commission, 2009) concerning the placing of plant protection products on the market states that pesticide residues detected after application consistent with Good Agricultural Practice (GAP) (FAO, 2008) shall not have any harmful effects on human health. As described above pesticide residues were found in many of the samples. In about 2-3\% of the samples, residues above the MRLs were found and often more than one pesticide residue per sample was found. An exceedance of an MRL will not necessarily causes health problems, because the MRLs are set based on GAP which may result in MRLs giving exposures well below any toxicological based guidance values, e.g. acceptable Daily Intake (ADI) and Acute Reference Dose (ARfD). If residues from a specific pesticide would cause health problems, the pesticide will not be approved for use according to Regulation (EC) 1107/2009 (EU Commission, 2009). When setting the MRLs, the evaluation of the pesticides is done on the individual pesticides and this do not cover effects from multiple residues. However, the pesticide residue monitoring results described above have been used to calculate the exposure for pesticides in the Danish population (Jensen et al., 2015) as mentioned in the introduction. In this paper the cumulative exposure was calculated using the Hazard Index method and as all pesticides had the same effect. The highest HI was calculated for children 4-6 years of age and amounted to 0.44 which is well below 1. It was concluded that there is no risk of adverse health effects following chronic cumulative exposure to the pesticides found in fruit, vegetables and cereals on the Danish market. As it is shown in this paper, samples of Danish have general have lower contents than samples of foreign origin so eating "Danish" whenever possible will reduce the exposure by a factor of 2(Jensen et al., 2015). 


\section{Conclusion}

A total of 17,309 samples were collected in the Danish monitoring programme during 2004-2011. Most of the samples were conventionally grown fresh fruits and vegetables (70\%), but conventionally grown cereals (10\%) and samples of animal origin (11\%) were also collected. Denmark is one of the EU member states that include the most samples in the pesticide monitoring programme in relation to population size. The results for the eight-year monitoring show that residues were more frequently found in samples of foreign origin than in samples of Danish origin (see Figure 2) both for samples with residues above and below the MRLs. In general, fruits and vegetables had higher frequencies of residues than the other groups of commodities; fruits had higher frequencies than vegetables. Overall, residues above the MRLs were found in $2.6 \%$ of the samples, most frequently in fruit. In plant commodities, 163 different substances were found in measurable concentrations. Residues exceeding the legal limits included 33 different pesticides. Residues of more than one pesticide (multiple residues) were found in $27 \%$ of all samples and in 98 different commodities. The results indicate that if Danish consumers choose commodities of Danish origin whenever possible, they will have a lower exposure to pesticides. This is especially the case for apples, pears, cucumbers, tomatoes, lettuce, spinach, potatoes, wheat flour and rolled oats. This is confirmed in the paper by Jensen et. al 2015, whose exposure calculations showed that choosing Danish commodities whenever possible reduced the exposure and the hazard by a factor of two.

\section{Acknowledgement}

Current publication was performed in the framework of the National Reference Laboratories for pesticide residues in cereals and feeding stuff, financed by the Danish Veterinary and Food Administration.

\section{References}

Arias, L. A., Bojacá, C. R., Ahumada, D. A., \& Schrevens, E. (2014). Monitoring of pesticide residues in tomato marketed in bogota, colombia. Food Control, 35(1), 213-217. http://doi.org/10.1016/j.foodcont.2013.06.046

Bargańska, Z., Ślebioda, M., \& NamieŚnik, J. (2013). Pesticide residues levels in honey from apiaries located of Northern Poland. Food Control, 31(1), 196-201. http://doi.org/10.1016/j.foodcont.2012.09.049

Chen, C., Qian, Y., Chen, Q., Tao, C., Li, C., \& Li, Y. (2011). Evaluation of pesticide residues in fruits and vegetables from Xiamen, China. Food Control, 22(7), 1114-1120. http://doi.org/10.1016/j.foodcont.2011.01.007

Christensen, H. B., Herrmann, S. S., Petersen, A., Poulsen, M. E., Jensen, B. H., \& Holm, M. (2008). Pesticidrester $i$ fødevarer 2007 Resultater fra den danske pesticidkontrol.

Christensen, H. B., Herrmann, S. S., Petersen, A., Poulsen, M. E., Lind, R. L., Holm, M., \& Cederberg, D. L. (2007). Pesticidrester i fødevarer 2006 Pesticidrester i fødevarer 2006.

Christensen, H. B., Petersen, A., Poulsen, M. E., Grossmann, A., \& Holm, M. (2006). Pesticidrester i fødevarer 2005 Resultater fra den danske pesticidkontrol.

Čuš, F., Česnik, H. B., Bolta, Š. V., \& Gregorčič, A. (2010). Pesticide residues and microbiological quality of bottled wines. Food Control, 21(2), 150-154. http://doi.org/10.1016/j.foodcont.2009.04.010

Danish Veterinary and Food Administration. (2005). Pesticidrester i fødevarer - resultater for 2004. https://www.foedevarestyrelsen.dk/SiteCollectionDocuments/25_PDF_word_filer til download/05kontor/Pesticidresterifdevarer2004.pdf

EFSA. (2011). The 2009 European Union Report on Pesticide Residues in Food. The EFSA Journal, 9(11), 1-125. http://doi.org/10.2903/j.efsa.2011.2430.

EFSA. (2013). The 2010 European Union Report on Pesticide Residues in Food. EFSA Journal, 11(3). http://doi.org/10.2903/j.efsa.2014.3694 
EFSA. (2014). The 2011 European Union Report on pesticide residues in food. EFSA Journal (Vol. 12). http://www.efsa.europa.eu/sites/default/files/scientific_output/files/main_documents/3942.pdf

EFSA. (2015). The 2013 European Union Report on pesticide residues in food. EFSA Journal (Vol. 13).

EU - Pesticides database. (2016). No Title. http://ec.europa.eu/food/plant/pesticides/eu-pesticidesdatabase/public/?event=homepage\&language=EN

EU Commission. (1996). COUNCIL DIRECTIVE 96/23/EC of 29 April 1996 on measures to monitor certain substances and residues thereof in live animals and animal products and repealing Directives 85/358/EEC and 86/469/EEC and Decisions 89/187/EEC and 91/664/EEC. Official Journal of the European Communities, (L), 10-32.

EU Commission. (2002). Commission Directive 2002/63/EC of 11 July 2002 establishing Community methods of sampling for the official control of pesticide residues in and on products of plant and animal origin and repealing Directive 79/700/EEC. Official Journal of the European Communities, 2, 30-43.

EU Commission. (2008). COMMISSION REGULATION (EC) No 1213/2008 of 5 December 2008 concerning a coordinated multiannual Community control programme for 2009, 2010 and 2011 to ensure compliance with maximum levels of and to assess the consumer exposure to pesticide residues in an. Official Journal of the European Union, 9-17. http://ec.europa.eu/food/plant/pesticides/max_residue_levels/enforcement/eu_multiannual_control_programme_en.htm

EU Commission. (2009). (EC) No 1107/2009. Official Journal of the European Union, 309(1), 1-50.

FAO. (2008). Good Agricultural Practices (GAP). http://www.fao.org/prods/gap/

International Standard Organization. (2005). ISO/IEC 17025 General requirements for the competence of testing and calibration laboratories. International Standard, 2005, 1-36.

Jensen, B. H., Christensen, H. B., Andersen, J. H., Petersen, A., Hilbert, G., Grossmann, A., \& Madsen, H. L. (2011). Pesticidrester i fødevarer 2010 Resultater fra den danske pesticidkontrol Pesticidrester i fødevarer 2010.

Jensen, B. H., Petersen, A., Christensen, H. B., Andersen, J. H., Hilbert, G., Grossmann, A., \& Holm, M. (2010). Pesticidrester i fødevarer 2009 Resultater fra den danske pesticidkontrol.

Jensen, B. H., Petersen, A., Nielsen, E., Christensen, T., Poulsen, M. E., \& Andersen, J. H. (2015). Cumulative dietary exposure of the population of Denmark to pesticides. Food and Chemical Toxicology : An International Journal Published for the British Industrial Biological Research Association, 83, 300-307. http://doi.org/10.1016/j.fct.2015.07.002

Jensen, B. H., Petersen, A., Andersen, J. H., Hilbert, G., Grossmann, A., \& Holm, M. (2012). Pesticidrester i fødevarer 2011 Resultater fra den danske pesticidkontrol Pesticidrester i fødevarer 2011.

Juan-Borrás, M., Domenech, E., \& Escriche, I. (2016). Mixture-risk-assessment of pesticide residues in retail polyfloral honey. Food Control, 67, 127-134. http://doi.org/10.1016/j.foodcont.2016.02.051

Knežević, Z., \& Serdar, M. (2009). Screening of fresh fruit and vegetables for pesticide residues on Croatian market. Food Control, 20(4), 419-422. http://doi.org/10.1016/j.foodcont.2008.07.014

Oliva, R., Gemal, a L., Nóbrega, a W., \& Araújo, a C. P. (2003). Pesticide monitoring programme of the Ministry of Health of Brazil. Food Additives and Contaminants, 20(8), 758-63. http://doi.org/10.1080/0265203031000138295

Ortelli, D., Edder, P., \& Corvi, C. (2005). Pesticide residues survey in citrus fruits. Food Additives and Contaminants, 22(5), 423-428. http://doi.org/10.1080/02652030500089903

Petersen, A., Jensen, B. H., Christensen, H. B., Andersen, J. H., Louise, K. H., Poulsen, M. E., Hilbert, G. (2009). Pesticidrester i fødevarer 2008 Resultater fra den danske pesticidkontrol. 
Poulsen, M. E., Andersen, J. H., Petersen, A., \& Hartkopp, H. (2005). Food monitoring, 1998-2003. Part 2. Copenhagen.

Rodríguez López, D., Ahumada, D. A., Díaz, A. C., \& Guerrero, J. A. (2014). Evaluation of pesticide residues in honey from different geographic regions of Colombia. Food Control, 37(1), 33-40. http://doi.org/10.1016/j.foodcont.2013.09.011

The European Parliament. REGULATION (EC) NO 396/2005 OF THE EUROPEAN PARLIAMENT AND OF THE COUNCIL of 23 February 2005 on maximum residue levels of pesticides in or on food and feed of plant and animal origin and amending Council Directive 91/414/EEC (2005). http://eur-lex.europa.eu/legalcontent/EN/TXT/PDF/?uri=CELEX:32005R0396\&from=EN

U.S. FDA. (2010). Pesticide Monitoring Program: 2010 Pesticide Report, 40. http://www.fda.gov/downloads/Food/FoodbornelllnessContaminants/Pesticides/UCM371200.pdf

U.S. Food and Drug Administration. (2011). Pesticide Monitoring Program 2011 Pesticide Report.

Uygun, U., Koksel, H., \& Atli, A. (2005). Residue levels of malathion and its metabolites and fenitrothion in postharvest treated wheat during storage, milling and baking. Food Chemistry, 92(4), 643-647. http://doi.org/10.1016/j.foodchem.2004.08.045 
1 Table 1. Number of samples analysed for the period 2004-2011 of Danish and foreign origin.

\begin{tabular}{lrrr}
\hline Foods & Danish & Foreign & Total \\
\hline Fruit and vegetables (fresh, frozen, processed) & 2844 & 9182 & 12026 \\
Cereals (including processed) & 717 & 1060 & 1777 \\
Wine & 2 & 273 & 275 \\
Meat & 1589 & 358 & 1947 \\
Milk and honey & 146 & 0 & 146 \\
Baby food & 28 & 38 & 66 \\
Organically grown fruit, vegetables and cereals & 358 & 714 & 1072 \\
(fresh, frozen, processed) & & 11625 & 17309 \\
\hline Total & 5684 & &
\end{tabular}

2 
1 Table 2. Percentage of samples with multiple residues. Only commodities where more than 30 samples were analysed 2 during the period 2004-2011 are included.

\begin{tabular}{lrlrlr}
\hline & $\begin{array}{l}\text { Samples, } \\
\text { multiple } \\
\text { residues }\end{array}$ & Commodities & $\begin{array}{c}\text { Samples, } \\
\text { multiple } \\
\text { residues }\end{array}$ & Commodities & $\begin{array}{c}\text { Samples, } \\
\text { multiple } \\
\text { residues }\end{array}$ \\
\hline Apricots & $52 \%$ & Lettuce & $15 \%$ & Potatoes & $1 \%$ \\
Apples & $39 \%$ & Limes & $50 \%$ & Rambutan & $26 \%$ \\
Aubergines & $11 \%$ & Mandarin, clementine & $93 \%$ & Raspberries & $31 \%$ \\
Bananas & $50 \%$ & Mangoes & $17 \%$ & Red currants & $51 \%$ \\
Beans with pods & $18 \%$ & Melons & $1 \%$ & Rice & $2 \%$ \\
Blackberry & $9 \%$ & Mushrooms, cult. & $8 \%$ & Rye flour & $6 \%$ \\
Blue berries & $20 \%$ & Oat kernels & $7 \%$ & Rye kernels & $2 \%$ \\
Carrots & $4 \%$ & Oranges & $82 \%$ & Spelt & $16 \%$ \\
Celery & $19 \%$ & Papaya & $61 \%$ & Spelt flour & $17 \%$ \\
Chilies & $48 \%$ & Parsley root & $5 \%$ & Spinach & $4 \%$ \\
Courgettes & $5 \%$ & Parsnip & $3 \%$ & Spring onions & $17 \%$ \\
Cucumbers & $17 \%$ & Passionsfruits & $37 \%$ & Star fruit & $32 \%$ \\
Grapefruits & $86 \%$ & Peaches, nectarines & $38 \%$ & Strawberries & $37 \%$ \\
Grapes & $49 \%$ & Pears & $44 \%$ & Sweet peppers & $17 \%$ \\
Rolled oats & $3 \%$ & Peas with pods & $61 \%$ & Tea & $13 \%$ \\
Kakis & $7 \%$ & Peas without pods & $6 \%$ & Tomatoes & $19 \%$ \\
Kiwis & $10 \%$ & Pineapples & $23 \%$ & Water melons & $8 \%$ \\
Leeks & $2 \%$ & Plums & $11 \%$ & Wheat flour & $7 \%$ \\
Lemons & $79 \%$ & Pomelos & $61 \%$ & Wheat kernels & $6 \%$ \\
\hline
\end{tabular}


1 Table 3. The ISO 3166 Codes (Countries) used in Figure 5. The codes can be found on

2 https://www.iso.org/obp/ui/\#search (Accessed on 7 July 2016)

\begin{tabular}{|lc|lc|}
\hline Country & Code & Country & Code \\
\hline Argentina & $\mathrm{AR}$ & Italy & $\mathrm{IT}$ \\
Australia & $\mathrm{AU}$ & Kenya & $\mathrm{KE}$ \\
Belgium & $\mathrm{BE}$ & Morocco & $\mathrm{MA}$ \\
Brazil & $\mathrm{BR}$ & Netherlands & $\mathrm{NL}$ \\
Chile & $\mathrm{CL}$ & Poland & $\mathrm{PL}$ \\
China & $\mathrm{CN}$ & South Africa & $\mathrm{ZA}$ \\
Denmark & $\mathrm{DK}$ & Spain & $\mathrm{ES}$ \\
Egypt & $\mathrm{EG}$ & Sweden & $\mathrm{SE}$ \\
France & $\mathrm{FR}$ & Turkey & $\mathrm{TR}$ \\
Germany & $\mathrm{DE}$ & United Kingdom & $\mathrm{GB}$ \\
Greece & $\mathrm{GR}$ & USA & US \\
Israel & $\mathrm{IL}$ & Unknown origin & UO \\
\hline
\end{tabular}

3

4 
1

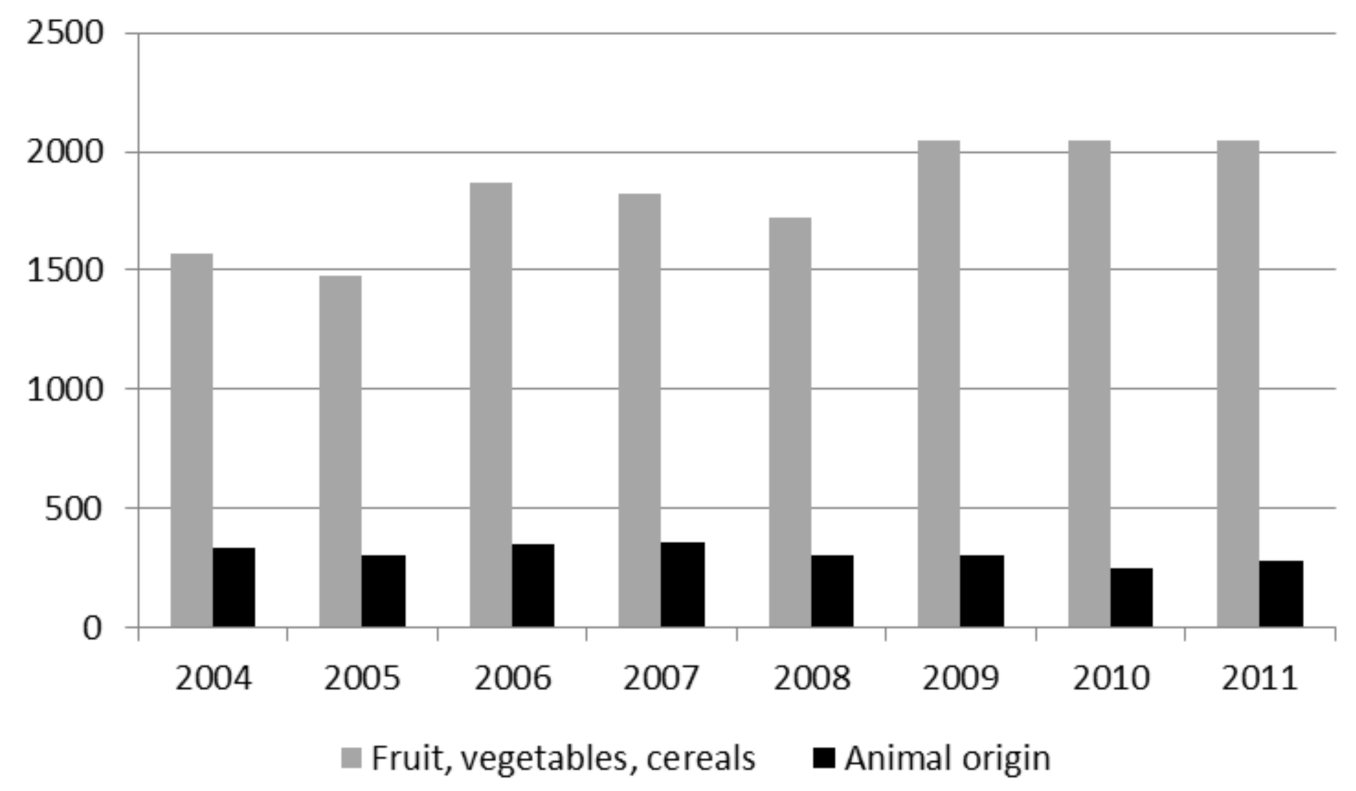

2

Figure 1. Numbers of fruit, vegetables and cereal samples as well as samples of animal origin analysed during the period 2004-2011.

5

6 


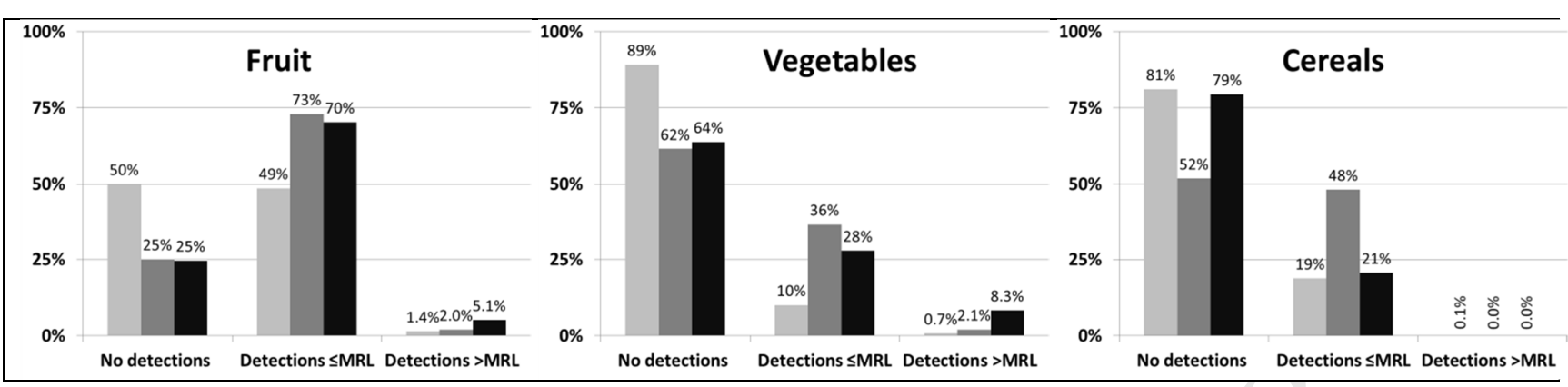

2

Figure 2. Pesticide residues detected in fruit, vegetables and cereals produced in Denmark (light grey bars), the EU (dark grey bars), and outside the EU (black bars). 


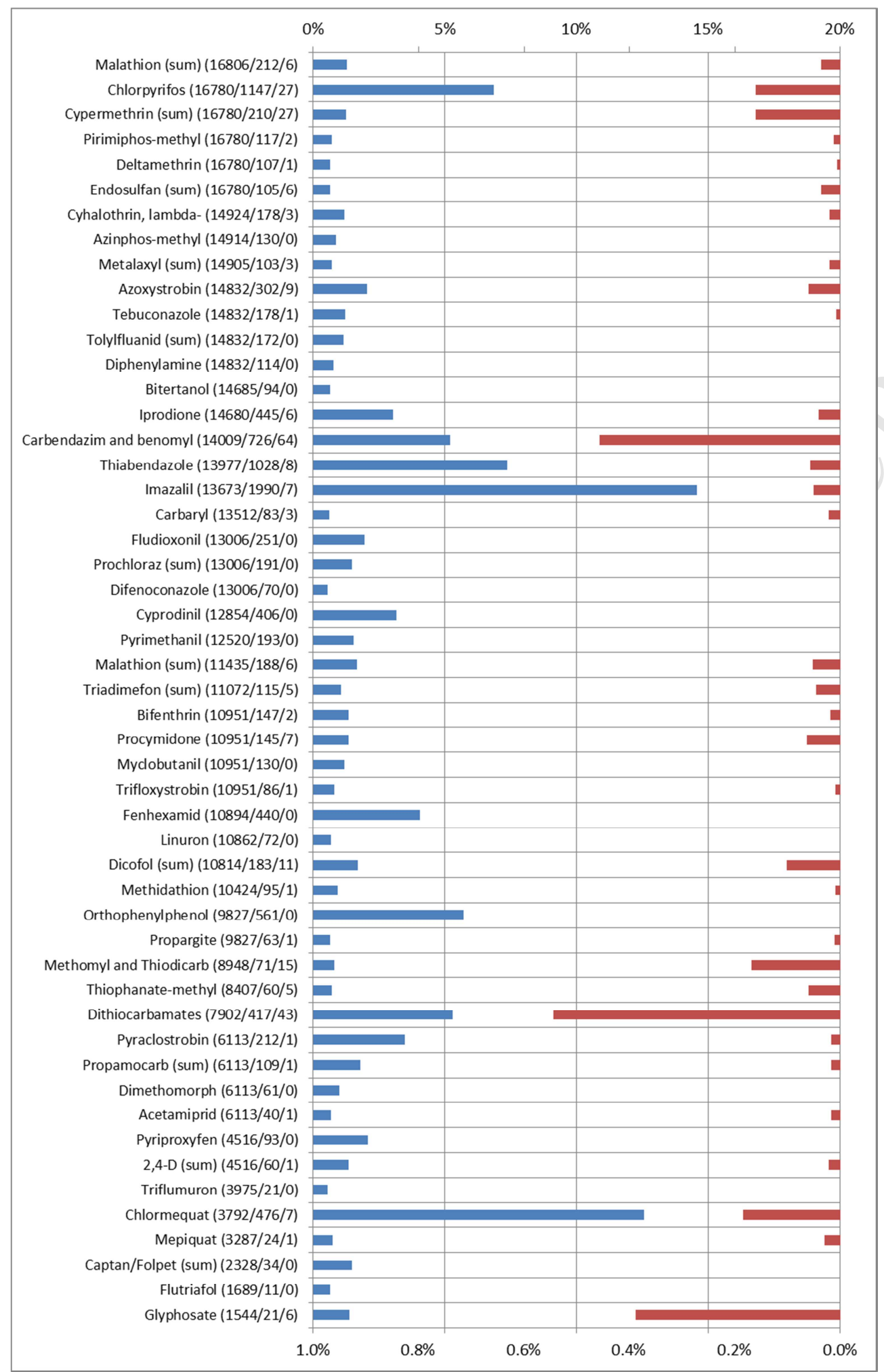

Figure 3. Detected pesticides. The pesticides that were detected in at least $1 \%$ of the plant product samples are ordered by the total number of samples analysed for the pesticide. The figures in brackets next to the name of the pesticide refer to the number of samples analysed for this pesticide, the number of samples with residues within the legally permitted concentrations and the number of samples exceeding the MRLs. The blue bars represent the percentage of samples within the legally permitted concentration. The axis for these results is shown at the top ( $0 \%$ $20 \%)$. The red bars represent the percentage of samples with residues above the MRL. The axis for these results is shown at the bottom $(0.0 \%-1.0 \%)$. 


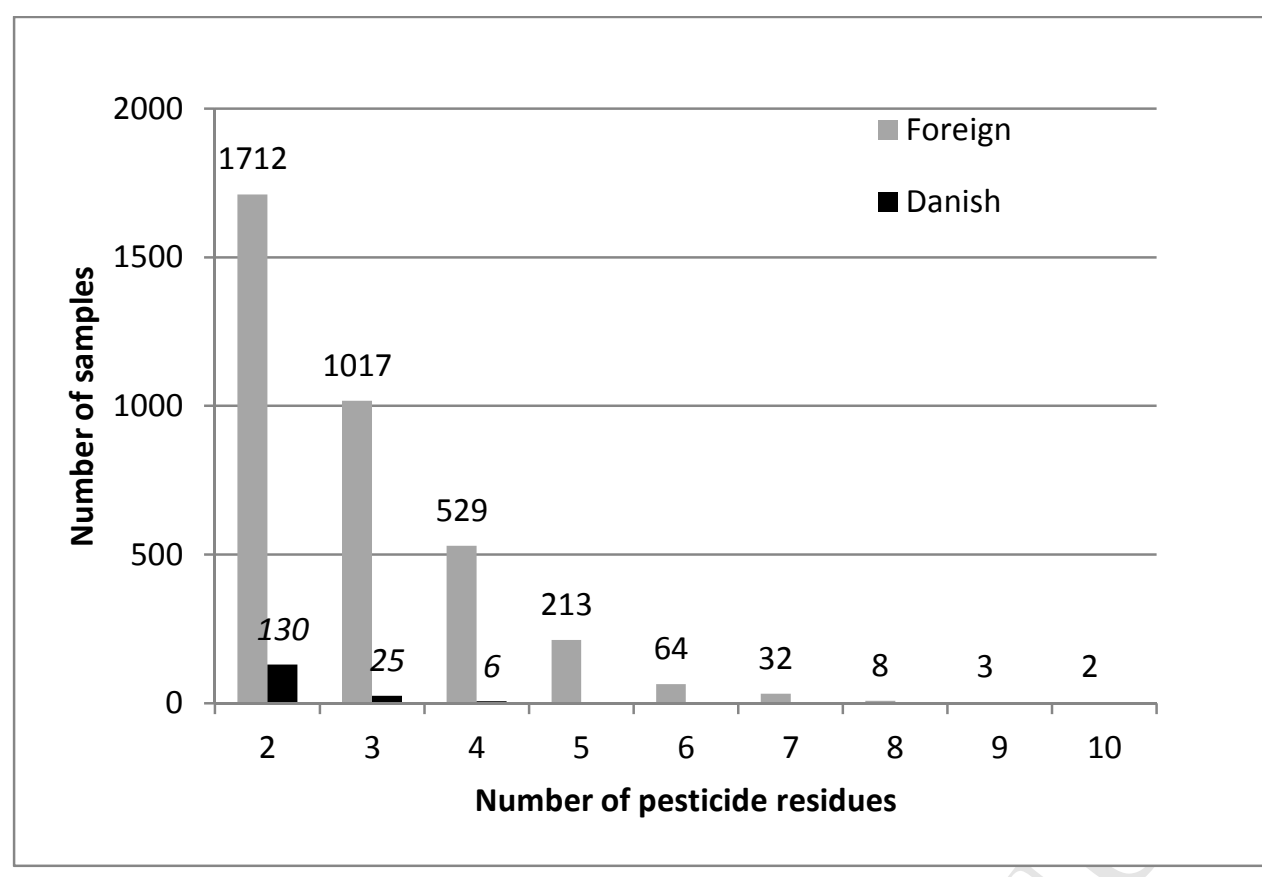

Figure 4. Number of samples with 2-10 residues per sample for the period 2004-2011. 


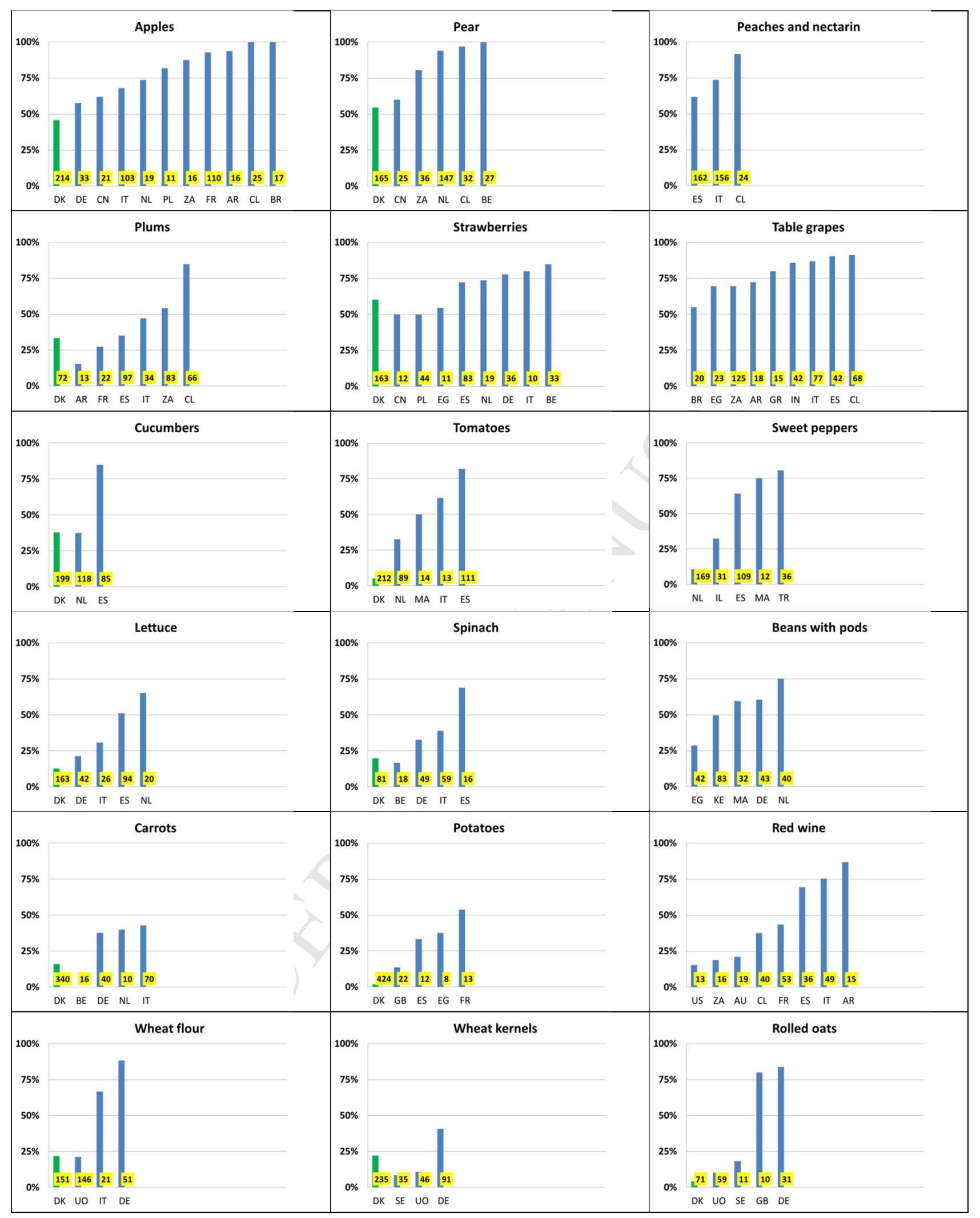

2 Figure 5. Frequencies of samples with pesticide residues. The figures marked in yellow are the number of samples 3 originating from the countries listed. The country codes are ISO 3166 codes (see table 3). 


\section{Highlights}

- Results of 17,309 samples from the Danish Pesticide Monitoring Programme 2004-2011

- Fruits and vegetables had higher frequencies of residues than the other commodities

- Residues were more frequently found in samples of foreign origin than in samples of Danish origin

- 163 different substances were found in measurable

- Multiple residues were found in $27 \%$ of all samples 